\title{
A DEDICATED PROGRAMME FOR DENTAL HYGIENISTS AND THERAPISTS IN EDINBURGH
}

Karen Walker, a highly experienced dental hygienist and respected speaker, will be speaking as part of the dedicated Dental Hygienist and Therapist programme at the ITI Congress UK \& Ireland 2021 this October. Karen's session is entitled 'Implementing Risk Assessing for Implants in Practice and Dealing with Complications'

Karen said: 'I will be following on from Ian Dunn's session on the importance of risk assessment for implant and periodontal patients. I will look at how to apply an effective risk assessment tool for daily practice in a practical way. I will also discuss the possible treatment complications to be aware of and how to deal with them effectively, offering treatment protocols and clinical guidance.

'This is definitely an area that needs improvement in practice. Many dental hygienists and therapists don't feel that they have sufficient knowledge to perform risk assessing, but they absolutely do. Dental hygienists and therapists already do so much when they see patients - much of the risk assessment and planning is done automatically. As such, they just need to be shown how to apply this in all aspects of patient care using simple tools.

'Through this session I hope the delegates will gain confidence in their abilities and take away a step-by-step sequence to put into practice immediately for effective treatment planning and risk assessing.

Other sessions within the Dental Hygienist and Therapist programme at the ITI Congress UK \& Ireland 2021 will cover treatment planning, establishing peri-implant health and EMS PerioFlow, with hands-on training available. It will also be the perfect opportunity for networking.

Karen said: 'The ITI is a global organisation, providing access to ideas and research from around the world for a broader overview of the evidence and protocols available. Event partner, Straumann, also supports this ethos for evidence-based implant dentistry. I have been a member of the ITI since 2011, having spoken at ITI Study Clubs and other ITI/Straumann educational events. I am delighted to be part of the

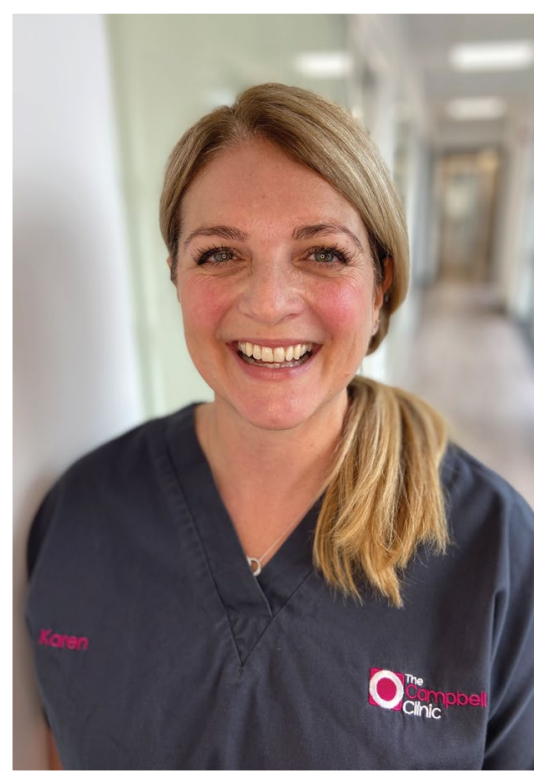

introduction of dedicated memberships for dental hygienists and therapists within the ITI UK \& Ireland. This membership will provide access to extensive education through study clubs, online events and further Congresses'.

The Dental Hygienist and Therapist programme has been developed by dental hygienists and therapists working in clinical practice, ensuring the evidence is relevant and the guidance is applicable to everyday practice.

The ITI Congress UK \& Ireland 2021 will be held on 1-2 October 2021 in Edinburgh. For more information, or to register for your place, visit https://events. iti.org/congressuk-ireland/.

\section{Most dental marses earn \&20k a year or less}

The British Association of Dental Nurses (BADN), the UK's professional association for dental nurses, released the results of their 2020 Salary Survey in March. The survey was conducted online between October and December 2020 and was completed by 1,265 respondents, $99 \%$ of whom were female. The Report compares the results of this survey with those of the survey conducted in 2013.

BADN President Jacqui Elsden said 'The 2020 BADN Salary Survey shows that the majority of dental nurses still earn $£ 20 \mathrm{k}$ per

How much did you earn (gross) in the year ending:

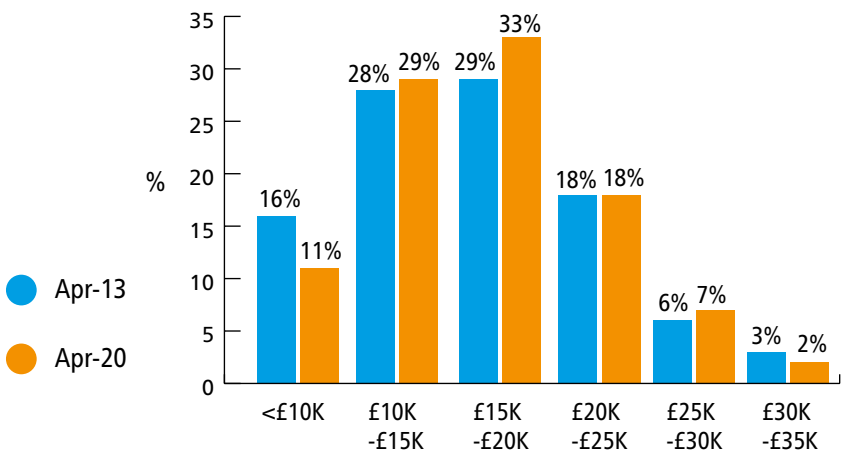

Fig. 1 Dental nurse salaries in 2013 and 2020

annum or less [Fig. 1], despite working full time and having been in the profession for more than ten years.

'From this, they are still expected to pay their own GDC registration fee (51\%), CPD costs (50\%) and BADN membership (91\%), receive no paid time off to complete their CPD requirements (87\%) and have no employee benefits (83\%). This is obviously why nearly one fifth $(16 \%)$ have a second job - half of whom have to have a second job to meet their basic living costs.

'Worryingly, 2\% are working without indemnity cover, $5 \%$ don't know if they have cover and more than half (55\%) depend upon their employer's cover!

'The results of the 2020 BADN Salary Survey reinforce BADN's call for dental nurses to be paid a salary which recognises their status as registered dental care professionals, their education, training and qualifications, and their invaluable role in the dental team.'

The full report can be accessed via www. badn.org.uk. 